\title{
Distinção entre óptica geométrica e física
}

\section{óptica: um estudo filosófico sobre seus antecedentes históricos}

\author{
Distinction between geometric optics and optical \\ physics: a philosophical study of its historical \\ antecedents
}

Ruslane Bião

Professora da Universidade Federal de Alagoas, Instituto de Ciências

Humanas, Comunicação e Artes;

E-mail: rubioliver@gmail.com

\section{Resumo}

Esse texto discute a diferença entre óptica geométrica e física óptica, através da transição entre diferentes teorias da visão do período medieval ao moderno. Partindo da óptica geométrica, assim determinada pela ideia de raios visuais em Euclides e Ptolomeu, chegouse à determinação da óptica experimental, ajustada à matemática, como concebeu Alhazen, partindo da física óptica, onde a luz e suas propriedades são objetos de modelos mecânicos. Essa transição é marcada definitivamente por Alhazen que, em seus trabalhos sobre matemática, desenvolveu uma teoria mecânica para demonstrar o movimento, sem, no entanto, introduzi-la na óptica experimental. Com a introdução da mecânica na matemática, a óptica como ciência física se erige a partir da determinação física do raio luminoso. Com isso, a ideia de movimento sai do limite de uma teoria mecânica em geometria e assume seu destaque como determinação de uma dinâmica na física mecânica, tal como ocorreu com Descartes e Newton.

Palavras-chave: Óptica. Refração. Demonstração. Sensação. Movimento.

\section{Abstract}

This text discusses the difference between geometric optics and optical physics, through transition between differents theories of vision from the medieval to the modern period. Starting from geometric optics, thus determined by the idea of visual rays in Euclides and Ptolemy, arrived at the determination of the experimental optics, adjusted to mathematics, as conceived by Alhazen, starting of the optical physics, where light and its properties are mechanical model objects. This transition is definitely marked by Alhazen, who, in his work on mathematics, developed a mechanical theory to demonstrate the movement, without, 
however, introducing it into the optics experimental. With the introduction of mechanics in mathematics, the optics as a physical science arises from the physical determination of the luminous ray. With that, the idea of movement goes beyond the limit of a mechanical theory in geometry and assumes its prominence as determining a dynamic in mechanical physics, as occurred with Descartes and Newton.

Keywords: Optics. Refraction. Demonstration. Sensation. Motion.

\section{Introdução}

Este artigo foi escrito com a finalidade de esclarecer onde termina a óptica geométrica para começar a física óptica, sendo necessário fazer uma abordagem sobre a teoria da visão sensitiva de Ptolomeu, essencialmente geométrica, pela razão histórica de corrigir problemas experimentais da óptica de Aristóteles. Entretanto, ao dar primazia a explicação geométrica, a teoria dos raios visuais de Ptolomeu antecipa resultados que não podem ser observados na experiência. $A$ questão que se coloca é que, se uma teoria da visão definida pelos raios visuais, corrigida por critérios experimentais, tal como fez Alhazen, pode ao mesmo tempo ser tão significativa e praticamente esquecida com o surgimento da trigonometria, área da geometria crucial para o surgimento da física óptica. Temos Descartes que, por um lado, desenvolve a lei dos senos para explicar os efeitos da refração e reflexão, por outro, temos Newton, que herda a lei da reciprocidade de Alhazen, que por sua vez utilizou a teoria dos raios visuais de Ptolomeu.

Blay, em La vue et la lumière, nos mostra que Ptolomeu desenvolveu uma óptica geométrica ao seguir os passos de Euclides para fundamentar sua teoria da visão. Ao tentar resolver os problemas dos efeitos visuais, Ptolomeu contribuiu para o processo de evolução da teoria euclidiana, e também deu origem à Óptica de Alhazen, físico árabe que forneceu os elementos constitutivos para a descoberta da lei de refração. A reformulação da teoria da visão ptolomaica se deve a critérios experimentais introduzidos na explicação do fenômeno luminoso, quando Alhazen buscou ajustar os problemas da geometria óptica deixados tanto por Ptolomeu quanto por Euclides.

Embora a Óptica de Ptolomeu tenha sido de contribuição relevante para Alhazen, este precisou romper com a teoria dos raios visuais para que o critério da 
experiência pudesse ser introduzido como um tipo de demonstração capaz de explicar o fenômeno luminoso, sendo talvez esse critério abandonado por Ptolomeu devido a forte influência da Geometria de Euclides. Autores como Martinho, Sarton e Rashed ajudaram nesse debate, com o objetivo de elucidar a forma como se dá a transição entre ótica geométrica e física ótica, considerando que Alhazen tornou necessária a introdução do princípio do movimento na geometria, a partir do qual será possível compreender a importância da mecânica nessa transição para o avanço da óptica.

Contudo, ver-se-á que Kepler foi importante, nessa transição, porque foi através de sua Óptica que o trabalho de Alhazen foi aperfeiçoado e difundido. Portanto, o diálogo que Descartes estabeleceu com Kepler mostrou-se fecundo no sentido de contribuir para a descoberta da anaclástica, conforme as Regras para direção do espírito. Ademais, o resgate da lei de reciprocidade de Alhazen, aperfeiçoado na Óptica de Newton, mostra como a física óptica se estabeleceu, em bases experimentais sistemáticas, juntamente com a geometria.

\section{O nascimento da óptica geométrica}

A luz e seus fenômenos luminosos despertam o interesse dos filósofos cientistas, por assim dizer, a milênios. No afã de investigar não só a essência, mas os efeitos que emanam da ação da luz, vários pensadores fizeram da óptica uma ciência que se inicia como uma física geométrica. Após isto, se desenvolveu a física óptica, que teve seu apogeu apenas no século XVII, cuja transformação da física geométrica em física óptica preencheu um conjunto de teorias físicas da luz que se desenvolveu a partir do problema da sensação visual.

O processo evolutivo da óptica como física geométrica, vale destacar, teve seu início com a investigação da reflexão e refração como propriedades essenciais da luz, objeto de interesse de Ptolomeu (161 d.C), que estabeleceu o índice de refração a partir da passagem ou mudança dos raios luminosos para diversos meios transparentes. Para Ptolomeu, a cor é o sentido próprio da visão a partir do qual o fluxo visual, como uma espécie particular de luz, permite sua percepção. Blay (2007, 
p. 120) afirma que a ideia de raios visuais de Euclides (300 a.C) tem sua formulação efetiva com Ptolomeu e será a partir deste que todos os estudos geométricos dos fenômenos luminosos e da sensação visual terão constituição geométrica, sobretudo com os cientistas árabes. A ideia de fluxo visual de Ptolomeu pressupõe a existência da emissão de luz oriunda do próprio olho, formando o que ele chama de cone visual, com seu vértice no centro do olho. Nesse sentido, esse fluxo tem emissão contínua e age juntamente com a luz natural para abranger os objetos visíveis através de seus raios visuais. Segundo Rodrigues Neto (2013, p.883-84), a ideia de raios visuais, em Euclides, se caracteriza por sua interceptação descontínua, pois, nem todas as partes do objeto visível podem ser vistas simultaneamente, já que a base do cone visual tem intervalos vazios, por causa do ângulo dos raios visuais. Portanto, a ideia de raios visuais, em Ptolomeu, é tida, por Rodrigues Neto, como uma abstração geométrica sem existência real.

Em princípio, parte-se da necessidade de se fazer uma abordagem dos antecessores de lbn al-Haytam (965-1039), mais conhecido por Alhazen, seu nome latino (em inglês conhecido por Alhacen), como responsável pelo resgate e aperfeiçoamento da óptica de Ptolomeu. Através dele é possível abordar o que fez seus sucessores, que adotaram o método de análise e síntese para investigar o fenômeno luminoso, tal como fizeram Descartes e Newton na física óptica.

Para termos a compreensão do que ocorre com a óptica alhacênica, devemos antes circunscrevê-la a partir do que pensou Ptolomeu sobre a refração. Mais conhecido no campo da Astronomia, sobretudo pelo seu principal tratado, o Almagesto, Ptolomeu desenvolveu estudos importantes no campo da Óptica, cujos resultados foram bastante significativos, embora pouco reconhecidos pelos cientistas modernos. Para Sarton (1927, p. 48), "O sistema ptolomaico teve supremacia a partir do Almagesto, obra onde Ptolomeu desenvolveu seu sistema geocêntrico, aceito até o século $\mathrm{XVI}$, mas que se tornou objeto de críticas e rejeição, na medida em que a Astronomia avança e torna suas observações mais precisas".

Segundo Lejeune (apud in PTOLÉMÉE, 1989, p. 33), o progresso da óptica moderna fez da Óptica de Ptolomeu objeto de interesse puramente histórico. Devese considerar aqui que os extratos da obra citada foram obtidos de forma online e fragmentada, pois seu conteúdo não é disponibilizado integralmente. Lejeune faz a 
tradução da Óptica de Ptolomeu, do latim para o francês, e na introdução à obra ele aponta às dificuldades de tradução, uma vez que essa obra foi traduzida do grego para o latim por Émir Eugenio de Sicilia, de língua árabe, e que pouco entendia de óptica. Essa importante obra tem cinco livros, sendo que o primeiro se perdeu e provavelmente foi nele que Ptolomeu fez seu estudo sobre o arco-íris. Segundo Sarton (1959, pp. 55-6) o quinto livro foi parcialmente recuperado e teve sua parte final perdida.

Entretanto, Ptolomeu foi sem dúvida um dos antecessores mais importantes da óptica moderna, pois ele antecipou a lei de refração de Alhazen, quando este desenvolveu o princípio de proporcionalidade, com medições visuais dos raios refratados, e a lei da reciprocidade, resgatado por Newton, onde os raios que refletem também retornam no mesmo ângulo de incidência.

Segundo Mach (1926, p 29), essas medições permitiram Ptolomeu desenhar tabelas de refração de $10^{\circ}$ à $80^{\circ}$. De acordo com essa visão, a razão entre o ângulo de incidência (a) e o ângulo de refração (b) permanece a constante ( $a / b=$ const.) para o mesmo par de meios. Essas observações, no entanto, não corresponderam às observações da lei de proporcionalidade encontrada por Alhazen, mas, a partir dessa constante, observa-se que, na Óptica de Ptolomeu, há uma elaborada tabela de refração do raio, que segue do ar até a água, onde é possível constatar uma diferença de $1 / 2^{\circ}$ entre $i$ e $r$. 


\section{Tabela de refração de Ptolomeu}

First real

\begin{tabular}{ccccc}
$\mathrm{i}$ & $\mathrm{r}$ & difference & value ot $\mathrm{r}$ & error \\
\hline $10^{\circ}$ & $8^{\circ}$ & $7^{\circ} 30^{\prime}$ & $7^{\circ} 28^{\prime}$ & $+32^{\prime}$ \\
$20^{\circ}$ & $15^{\circ} 30^{\prime}$ & $7^{\circ}$ & $14^{\circ} 51^{\prime}$ & $+39^{\prime}$ \\
$30^{\circ}$ & $22^{\circ} 30^{\prime}$ & $6^{\circ} 30^{\prime}$ & $22^{\circ} 1^{\prime}$ & $+29^{\prime}$ \\
$40^{\circ}$ & $29^{\circ}$ & $6^{\circ}$ & $28^{\circ} 49^{\prime}$ & $+11^{\prime}$ \\
$50^{\circ}$ & $35^{\circ}$ & $6^{\circ} 30^{\prime}$ & $35^{\circ} 3^{\prime}$ & $-3^{\prime}$ \\
$60^{\circ}$ & $40^{\circ} 30^{\prime}$ & $5^{\circ}$ & $40^{\circ} 30^{\prime}$ & 0 \\
$70^{\circ}$ & $45^{\circ} 30^{\prime}$ & $4^{\circ} 30^{\prime}$ & $44^{\circ} 48^{\prime}$ & $+42^{\prime}$ \\
$80^{\circ}$ & $50^{\circ}$ & & $47^{\circ} 36^{\prime}$ & $+2^{\circ} 24^{\prime}$ \\
\hline
\end{tabular}

Figura 1: (LEJEUNE, Apud in SARTON, 1959, p.56) ${ }^{1}$.

Essa diferença de $1 / 2^{\circ}$ permanece constante, o que nos sugere que esse valor é resultado do princípio de proporcionalidade de Ptolomeu. Contudo, ao se estabelecer valores reais de refração, ou seja, àqueles valores obtidos na observação, encontra-se erros que não correspondem aos índices da segunda coluna. Isso mostra que a observação dos índices de refração não são os mesmos obtidos pelo princípio de proporcionalidade. Por isto, ao anunciar, no livro $\mathrm{V}$ de sua Óptica, a lei geral de seu estudo experimental, ao medir as diferenças concretas existentes entre ângulos de incidência e refração, Ptolomeu antecipa uma generalização de forma precipitada (BOYER, 1987, p. 127). Por isto, Lejeune (1959, apud in SARTON, p. 57) conclui que Ptolomeu pôde ter sido induzido por autoridades gregas, que buscavam justificações matemáticas para teorias físicas, assim como fez Euclides, em suas tentativas de fazer demonstrações geométricas para explicar o comportamento da luz².

1 Figura da tabela é fornecida por Lejeune, em "Les tables de rétraction de Ptolémée" (Annales de la Société scientifique de Bruxelles 60 [1946], 93-101), segundo Sarton.

${ }^{2}$ Aristóteles desenvolveu uma óptica essencialmente experimental. Foi constatado, porém, que a óptica aristotélica necessitava de justificação teórica a partir da matemática. Com isso, a óptica 
A teoria dos raios visuais, segundo a qual o órgão da visão emite raios luminosos para Euclides, é um postulado presente da Óptica de Ptolomeu. Os olhos emitem raios, que circunscrevem o objeto visto, em forma de cone visual, cujo ápice atinge o centro do olho. Desse modo, os raios visuais seguem em linha reta, abarcando o objeto visto, formando uma teoria que servirá de base para a Óptica de Ptolomeu, numa formulação detalhada da refração como fenômeno luminoso e da sensação visual. Certamente, Euclides exerceu forte influência na Óptica de Ptolomeu e, por essa razão, Sarton (/bid., p 57; grifo meu) considera que "[é] certo que Ptolomeu fez algumas observações com cuidado; ele não as continuou, mas as generalizou prematuramente e constituiu sua tabela a priori".

Já os postulados da Óptica de Euclides expressam a existência do raio visual como elemento geométrico, abrindo o caminho para uma óptica ptolomaica essencialmente geométrica, o que pôde ter gerado a dificuldade de adequar o princípio de proporcionalidade às observações. Quando Ptolomeu formula o princípio de proporcionalidade, para determinar a situação geométrica da refração do raio luminoso, utiliza um quadrante graduado imerso na água para ser levado ao centro, que hoje chamamos de baptistir.

Ptolomeu constrói o baptistir, um goniômetro com uma escala angular ao longo do seu perímetro com uma precisão de $0,5^{\circ}$, cujo centro coincide com a interface entre os meios dielétricos que ele explora. Ele escolhe os dioptros ar-água, ar-vidro e vidro-água, varia os ângulos de incidência entre $10^{\circ}$ e $80^{\circ} \mathrm{em}$ unidades de $10^{\circ}$ (medidas a partir da normal para a interface) e mede os ângulos de refração correspondentes. Ele, em seguida, realiza um estudo detalhado dos seus resultados e produz uma lei empírica, precisa o suficiente para ser de uso prático ainda em nossos dias. Curiosamente, poucos fizeram uso dela, Ptolomeu incluído (MARTINHO, 2013, p. 2).

Para Martinho (/bid., pp. 50-2), o baptistir é um instrumento que chega a valores angulares aproximados, mas as discrepâncias dos valores reais, dados na observação, podem ser corrigidas se a fórmula de Bhaskara, que determina o seno de um determinado ângulo com maior precisão, for introduzida. O que se deve chamar a atenção aqui é que, mesmo sendo encontradas discrepâncias angulares

posterior se dedicou a corrigir os defeitos da óptica de Aristóteles através da geometria, mas sem ajustá-la a critérios experimentais consistentes. 
com a aplicação do princípio de proporcionalidade, o baptistir, inventado a mais 1.800 anos, é um instrumento atual e que permite determinações muito precisas da situação angular dos raios incidentes e refratados:

\section{Baptistir de Ptolomeu}

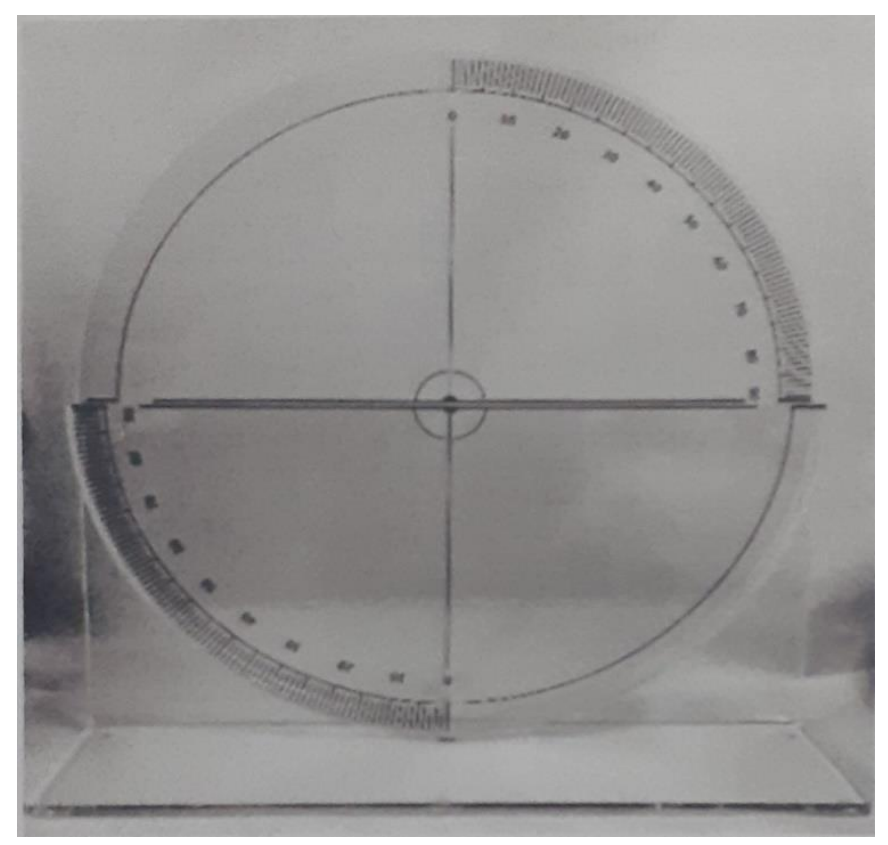

Figura 2: Baptistir reproduzido por Martinho (2013, p.31).

Em contrapartida, o princípio de proporcionalidade, tal como foi apresentado por Ptolomeu, não se aplica ao quadrante completo, pois as observações mostram que as discrepâncias são maiores entre os valores dos raios incidentes menores que $30^{\circ}$ e maiores que $60^{\circ}$ (Veja Figura 1). O fato é que Ptolomeu pertence a uma tradição grega que atribui maior importância à Geometria, sobretudo a de Euclides, para assim desenvolver uma óptica geométrica que faça uma descrição da imagem visual causada por fenômenos luminosos ou por sensação visual. Portanto, a tradição da geometria grega ainda não havia reconhecido a importância das observações, pois Ptolomeu não conseguiu observar essas discrepâncias:

Os antigos ainda não entendiam a supremacia das observações como nós fazemos e usamos mais resultados observacionais como indicadores, justificando a formulação de uma teoria, até como guias para ajudar viajantes a encontrar o caminho certo. Antes de julgá-los muito severamente, devemos lembrar que suas observações eram geralmente tão pobres, que possivelmente os 
resultados das observações não poderiam ter com eles a mesma autoridade que tem conosco (SARTON, 1959, p. 57).

Rigorosamente, não sabemos exatamente em quais circunstâncias suas observações foram feitas. O que Sarton nos chama atenção é que a autoridade da observação é muito posterior à época de Ptolomeu, e mais avançada devido às descobertas conquistadas com o uso de observações mais rigorosas e adequadas à geometria. $\mathrm{O}$ avanço da trigonometria, no período moderno, foi o que possibilitou o desenvolvimento de uma óptica mais precisa porque nela se explicou as relações existentes entre os lados e os ângulos do triângulo, favorecendo a descoberta da lei dos senos de incidência e de refração utilizada por Descartes. O fato é que Ptolomeu, apesar dos erros observacionais, chegou bem próximo da lei de refração, embora desconhecesse a lei dos senos, efetivamente desenvolvida com o avanço da trigonometria. Embora a Óptica de Ptolomeu tenha se desenvolvido como uma óptica geométrica, longe de ser uma física óptica, sua teoria do fluxo visual, segundo o qual se concebe um tipo de luz nos olhos, torna o sentido visual dependente desse fluxo:

[...] um objeto é mais bem visto, seja quando o fluxo visual o aclara, seja quando a luz cai sobre ele abundantemente. Por exemplo, o que é percebido na visão direta é mais bem visto que do que o que é percebido por reflexão ou refração. Entretanto, numerosos raios [diretos] se deterioram quando se distanciam muito. $O$ que é observado pelos dois olhos é mais bem visto que com um único. O que tem ama luz própria é mais bem visto que o que recebe luz de alhures. $E$ entre esses últimos [os objetos claros] é mais bemvisto o que a luz chega de uma fonte maior ou de fontes numerosas (PTOLÉMÉE, 1989, § 18).

Dessa maneira, Ptolomeu atribui ao fluxo visual duas capacidades: a de ver e a de iluminar. A visão, por um lado, pode se embaraçar com a perturbação do ar que cerca o objeto e por isto pode não ser visto claramente se os olhos estiverem distantes dele; por outro, se os olhos estiverem próximos do objeto visto, o fluxo visual condensará seus raios de tal modo, que o objeto passa a ser totalmente circunscrito por eles e visto com clareza. O que nos chama atenção aqui é o fato de Ptolomeu acreditar que, no uso de suas capacidades, os olhos têm de iluminar o objeto visto, adequando-se ao postulado euclidiano de que os raios visuais formam um cone e se propagam em linhas geométricas. Tanto é que, segundo Blay (2007, 
p. 122), "[...] é sobre essa base euclidiana que uma ciência geometrizada se constitui e encontra sua forma mais consumada na "Óptica" de Cláudio Ptolomeu". Assim, a luz e suas propriedades se tornam objeto de uma óptica geométrica que determina a existência de seus elementos inexprimíveis na observação.

Alhazen foi um dos maiores divulgadores de óptica ptolomaica. Em sua obra De aspectibus (1572), há uma clara transformação da óptica onde os fenômenos luminosos e a sensação visual são determinados pelo método experimental: o livro I é dedicado à visão de modo geral; o II às propriedades visíveis; o III sobre os erros da visão; o IV,V e VI tratam da visão por reflexão; e o VII é dedicado ao estudo da refração (BOYER, 1987, p. 125). Nesse importante tratado, sobretudo nos dois primeiros livros, há o interesse de Alhazen em refutar a teoria dos raios visuais de Ptolomeu, pois, segundo ele, a luz e seus fenômenos luminosos penetram nos olhos para os objetos serem vistos. A percepção visual não possui qualquer agente físico para iluminá-los. Sendo assim, o processo visual, em Alhazen, recebe a seguinte interpretação:

Novamente, achamos que a visão não percebe nenhum objeto visível a menos que exista no objeto alguma luz que o objeto possua de si mesmo ou que irradie sobre ele a partir de outro objeto. E se o objeto é escuro e não tem luz alguma nele, não será percebido ou sentido pela visão. Também achamos que quando o olho está em lugar escuro, percebe os objetos a frente se forem iluminados por alguma luz e se a atmosfera intermediária for contínua e ininterrupta por algum corpo opaco. Se o objeto estiver em um local escuro que não tem luz, e o olho está situado em um lugar iluminado, então esse objeto não será percebido ou sentido pela visão. E achamos que esse estado de coisas é uniforme e sem variação ou mudança. Isso, portanto, prova que se o objeto tem alguma luz nele, e é um dos possíveis objetos da percepção visual, e se a luz nele está acima do limite que pode ser percebido pela visão, então a visão perceberá que o objeto e o ar que envolve o olho estão ou não iluminados por uma luz diferente da que está no objeto. (AL-HAYTHAM, I, 1989, pp. 8-9).

A visão, portanto, é órgão receptor da luz e seu papel é de percepção sensorial. A luz é, então, o agente físico que deve ser objeto de investigação de forma específica para dele estabelecer as determinações de suas propriedades. No "Discurso da luz", Alhazen irá delimitar o campo de atuação da óptica, mostrando a importância de unir matemática e física: no estudo da luz, sua essência, seus raios 
luminosos, os corpos transparentes por onde penetra, pertencem à física; na sua propagação, sua forma e figura, seu comportamento em corpos transparentes pertence à matemática (Apud in RASHED, 1968, p. 205). Embora Alhazen conceba o estudo da luz a partir da junção entre matemática e física, na investigação de sua essência e propriedades, ainda assim sua óptica se estabelece no domínio da física geométrica, segundo a qual a noção de movimento ainda não está desenvolvida como objeto de uma ciência mecânica. Segundo Blay (2007, p. 132), o que realmente difere a óptica como ciência geométrica da óptica como ciência física é o estudo da luz e suas propriedades associado à construção de modelos mecânicos desta em relação àquela. Somente no século XVII que a mecânica será desenvolvida como ciência física, pois "a análise geométrica se torna secundária em relação à determinação da constituição física do que se denomina raio luminoso; essa física do raio luminoso deve, além disso, encontrar as leis da óptica geométrica" (/bid., p. 132).

Além disso, destacado como grande matemático de sua época, Alhazen concebe análise e síntese como procedimentos geométricos necessários para a demonstração de existência e construção geométrica, e parte dos elementos essenciais das secções cônicas (parábola, hipérbole, elipse), objetos inexprimíveis com régua e compasso. Segundo Rashed (1994, p. 128), Euclides concebeu sua noção de movimento para demonstrar o trajeto contínuo de curvas planas apenas no Livro XI dos Elementos. Sendo assim, Alhazen se baseia na análise e síntese como procedimentos da prática matemática, não só para tornar possível a demonstração do movimento das curvas planas coordenadas, mas para desenvolver uma teoria mecânica, na construção das curvas contínuas e nos sólidos geométricos. Essa abordagem de Rashed (Ibid., p.127) examina o interesse de Alhazen em resolver o problema da demonstração de objetos inexprimíveis sem o uso da régua e do compasso; portanto, análise e síntese, em Alhazen, não chegam a ser um método, mas são procedimentos requeridos na prática matemática para demonstrar a existência de uma determinada classe de objetos geométricos. Na matemática, porém, o procedimento de análise serve antes para descobrir se objetos sólidos podem ser conhecidos a partir de elementos imutáveis (reta, círculo, ângulo), caso seja, sua existência é demonstrada e a partir daí a síntese segue seu caminho na 
construção geométrica. A demonstração, então, tem o significado de prova assim como a experiência como veremos mais adiante.

Observe que o desenvolvimento de uma teoria mecânica das curvas, em Alhazen, é um importante passo para a compreensão do que ele estabelece na óptica, principalmente no Livro VII, Sobre Refração, em De aspectibus. Observe, então, a Introdução de Smith a este Livro:

Depois de definir a agenda para o capítulo 1, Alhazen prossegue no capítulo 2 ao estabelecer os princípios fundamentais que governam a refração. Isso ele faz com base em um aparelho experimental, análogo ao concebido no livro 4 para demonstrar os princípios fundamentais da reflexão. Usando o mesmo aparelho, no capítulo 3 descreve um método experimental que determina os ângulos da refração para detalhar os ângulos de incidência quando a luz atravessa obliquamente do ar para a água, do ar para o vidro, do vidro para o ar e do vidro para a água. Alhazen se volta, no capítulo 4, para um conjunto de testes empíricos para provar que um ponto do objeto visto por meio de refração é percebido ao longo do raio refratado, sendo a sua imagem deslocada. Ele termina o capítulo mostrando que tal deslocamento afeta a observação das estrelas e da lua no horizonte, nelas fazendo refração atmosférica para parecer elevados. Tendo feito esses pontos, ele dedica o capítulo 5 a uma discussão da localização da imagem para demonstrar empiricamente que a imagem de um ponto do objeto visto, em uma inclinação através de uma interface refrativa, está localizada onde o raio refratado intercepta a queda normal do ponto do objeto para a interface refrativa. Com base nessa demonstração empírica, ele conclui o capítulo 5 com uma série de dez teoremas, provando que qualquer ponto do objeto visto através de qualquer interface refrativa, seja plana, esférica convexa ou esférica côncava, produzirá apenas uma imagem. No capítulo 6, Alhazen explica como essas imagens são atualmente vistas e como sua aparência é afetada pela refração, fechando o capítulo com uma demonstração empírica de que tudo é visto por meio de raios refratados através das túnicas transparentes do olho. Ele então fecha o livro 7, no capítulo 7, com uma breve descrição das percepções por refração, seu foco neste capítulo é a aparente ampliação ou diminuição de imagens vistas através de interfaces refrativas. A pièce de résistence de sua análise conclusiva é sua explicação da llusão da Lua com base nos fatores tanto psicológicos quanto ópticos (ALHACEN, 2010, p. xv). 
Primeiramente, destacamos a importância que Alhazen dá à demonstração empírica quando examina o modo com o qual a luz se comporta ao atravessar o meio transparente, para chegar, no capítulo V, do Livro VII, à determinação de teoremas que provam o modo pelo qual a imagem é produzida. Vimos anteriormente que análise e síntese, em Alhazen, nada têm a ver com um método investigativo propriamente dito, mas antes são procedimentos necessários na prática matemática. Mas, se formos indagar o que deve vir antes do método empírico, em Alhazen, iremos nos deparar com a ausência de um método hipotético-dedutivo, no qual hipóteses devem ser testadas antes, na experiência, para serem confirmadas ou refutadas depois. Como consequência, a óptica de Alhazen, segundo a Introdução de Smith, nos mostra que "[...] esses experimentos foram projetados não para testar, mas para confirmar hipóteses já aceitas a priori (Ibid., p. c-ci)". Na verdade, é difícil explicar a ordem das investigações em Alhazen, sobretudo quando ele tenta adequar experiência à matemática no exame da refração, pois, ao introduzir a noção de movimento na óptica geométrica, ele apresenta dificuldades para demonstrá-la na experiência. Essa dificuldade, talvez, tenha origem justificável no próprio esforço de Alhazen em redefinir a óptica de Ptolomeu, principalmente ao se obstinar a corrigir os erros de observação ptolomaica. Um aspecto importante para observar é que a prova, para Alhazen, se estabelece na experiência, que exerce papel fundamental na constituição do capítulo 4 do Livro VII, Sobre Refração. Portanto, será o método experimental que fará de Alhazen não só um antecipador da ciência moderna, mas um estudioso fiel da óptica de Ptolomeu, pois, segundo Rashed:

[...] Ptolomeu fez frente a lbn al-Haytham, ocultou-lhe a importância e a novidade do resultado de lbn Sahl. Mas esse retorno a Ptolomeu incitou Ibn al-Haytham a perseguir a pesquisa quantitativa; mesmo se, com efeito, ele dispusesse dos quadros de seu predecessor, ele devia calcular outros valores, ao menos dos ângulos de desvio e as diferenças de primeira ordem, cercado de uma óptica e de uma teoria da prova renovadas (Apud in, BLAY, 2007, p. 130).

Segundo Blay, Alhazen tinha conhecimento da geometria de lbn Sahl (9401000 d.C), seu contemporâneo, que antecipa a lei de refração por uma relação inversa do índice de refração, considerando dois meios diferentes. Enretanto, Alhazen prefere seguir o caminho quantitativo, em situações experimentais, para 
assim requalificar a óptica ptolomaica. Assim como Ptolomeu, Alhazen também desconhecia a lei dos senos, mas, ao chegar próximo à lei de refração, contribuiu significativamente para o avanço da ciência moderna, que erigiu suas teorias científicas, destacando a sistematização dos modelos empíricos ajustados à física, com o desenvolvimento de leis científicas a partir de teorias justificadas matematicamente. Se, por um lado, o movimento em Alhazen é objeto de elaboração de uma teoria mecânica de curvas geométricas, de extensão contínua, por outro, o movimento, como objeto da dinâmica de uma física mecânica, vai possibilitar o desenvolvimento de uma física óptica, que se estabeleceu por leis físicas do movimento somente no século XVII, como é o caso de Descartes e Newton.

Para chegar perto da lei de refração, Alhazen precisou empregar um modelo mecânico no estudo da refração:

Finalmente, a dinâmica da análise de refração de Alhacen levanta
dificuldades. Para começar, essa análise está baseada na suposição
de que refrações ocorrem diretamente no ponto de entrada em um
meio mais denso ou mais raro. Sendo assim, as forças de
resistência ao longo da vertical e horizontal devem ser exercidas
instantaneamente e, como resultado, a mudança de movimento
também deve ser instantânea. Não só essa mudança instantânea
de movimento é filosoficamente problemática, mas sem
contrapartida no mundo físico, onde toda mudança de movimento,
por mais abrupta que seja, envolve algum estágio de transição de
desaceleração ou aceleração (SMITH, Apud in ALHACEN, 2010, p.
Ixii).

Essa dificuldade decorre não somente da ausência de uma física óptica, que aplica as leis do movimento para explicar a mudança, mas também pela ausência de uma adequação satisfatória entre movimento e experiência. Como vimos, desde a tradição grega a ciência natural se desenvolve a partir de pressupostos matemáticos, dando-lhes, com a elaborada óptica geométrica, uma explicação obstinada ao fenômeno luminoso e sua sensação visual. Na ausência de um sistema mecânico estruturado para lidar com a mudança, a física óptica se ergueu na busca de respostas para os problemas do movimento e assim superar a óptica geométrica. 
Desse modo, considera-se que movimento da luz provoca seu choque em outros corpos, que se movem ao seu redor, causando seu desvio, tanto de reflexão quanto de refração, em corpos mais ou menos densos. Logo, o ângulo de incidência é determinante para seu desvio, pois a direção de seu movimento irá alterar a rapidez de sua propagação nos corpos em que a luz se esbarra, aumentando ou reduzindo seu movimento. Para a física óptica avançar, o problema da sensação visual precisou ser deixado de lado para que o estudo da propagação da luz e da gênese da cor fosse desenvolvido. Esse avanço só ocorre no século XVIl:

Esse tipo de aproximação foi verdadeiramente iniciado por Descartes. No mundo pleno cartesiano, a propagação da luz é caracterizada por uma tendência ou inclinação ao movimento das esferas da matéria sutil, preenchendo todos os céus; ele assinala, além disso, que essas esferas, além de tendência ao movimento retilíneo, produzindo a sensação da luz, podem igualmente girar ou ao menos ter uma tendência à rotação sobre elas mesmas. Esses múltiplos movimentos ou tendência à rotação que Descartes liga a sensação das cores (BLAY, 2007, p 132).

Apesar das dificuldades, é inconteste o avanço da óptica alhacênica, visto que Sabra (apud in AL-HAYTHAM, 1989, p. Ixi), ao traduzir os três primeiros Livros da Óptica de Alhazen, nos mostra que este é o primeiro tratado a ultrapassar a óptica ptolomaica, pois, ao romper com a teoria dos raios visuais de Ptolomeu, o método experimental é sistematizado como jamais foi, para além do que fez Ptolomeu em sua óptica. Certamente, a ruptura com a teoria dos raios visuais é um passo importante para o avanço da óptica de Alhazen, pois significa também uma ruptura com a óptica euclidiana, que também defende a teoria dos raios visuais. Ademais, a lei da reciprocidade em Alhazen antecipa o avanço da óptica moderna, pois ela estará presente, porém reformulada, na óptica de Huygens e Newton.

\section{O nascimento da física óptica}

A revolução científica do século XVII traz consigo uma história da ciência marcada por teorias científicas com um objetivo comum, o de investigar e elucidar a natureza da luz, em parte pelo avanço significativo da Astronomia, após longos 
séculos de aceitação da Astronomia ptolomaica. As descobertas realizadas por Kepler, que o tornaram mais conhecido pela teoria das leis do movimento dos planetas, também se dirigiram ao campo da óptica, lançando assim uma base para outras teorias que aperfeiçoaram a física óptica, a saber, a de Descartes (15961650) e Newton (1643-1727).

Convém chamar atenção sobre a relação que Descartes estabeleceu com Kepler, considerando o que pensou Alhazen, que contribui decisivamente para o desenvolvimento da óptica moderna. Não é forçado dizer que Alhazen pode ser considerado o pai da óptica, pois ele desenvolveu um trabalho avançado para seu tempo, que antecipou a lei de refração estabelecida por Descartes e Snell (15911626). Deste se estabeleceu a lei de refração experimental antes mesmo de Descartes tê-la estabelecido dedutivamente. Entretanto, Descartes não chegou a conhecer a formulação de Snell, pois este não chegou a publicá-la, mas seus manuscritos, que se perderam ao longo do tempo, foram conhecidos por Huygens (1629-1695). Porém, a formulação cartesiana foi mais amplamente difundida, chegando a ser conhecida por Newton que, através dela, reformulou o princípio de reciprocidade, já estabelecida por Alhazen, como veremos mais adiante.

Também não é forçado dizer que Alhazen é um dos cientistas medievais mais ousado, pois desenvolveu um método científico arrojado, servindo de base para Galileu e Kepler, colaborando para a sistematização da experiência com a matemática. Sendo assim, é importante considerar que Descartes, numa de suas correspondências a Mersenne (31 de março de 1638), reconhece que Kepler foi o seu primeiro mestre em óptica (DESCARTES, 1996, p. 85), porém, se defende de uma acusação:

Aquele que me acusa de ter copiado de Kepler as elipses e as hipérboles da minha Dióptrica deve ser ignorante ou malicioso; pois, por elipse, não me recordo do que Kepler fala, ou se ele fala, é certamente para dizer que ela não é a anaclástica que ele procura; e por hipérbole, lembro-me muito bem que ele pretende demonstrar concretamente que ela não é, embora diga que ela não é muito diferente. (/bid., p. 84).

O que Descartes diz com isto é que Kepler se dedicou a demonstrar a hipérbole para medir a refração dos raios luminosos, mas a curva anaclástica, que 
é aquela que reúne vários raios, de direções distintas, em um único ponto para resultar na refração convergente de raios, não foi de Kepler objeto de investigação. Ao contrário, Kepler (2000, p. 122) se ocupa da hipérbole para medir o ângulo de refração, tal como ele demonstra na Óptica, ao afirmar que, se a inclinação dos raios refratados igualmente se submeter "[...] as regras da hipérbole, a hipérbole será dada e a superfície hiperbólica calculará as refrações". Mas a anaclástica cartesiana tem outra função, que é a de calcular a proporção existente entre os ângulos de incidência e de refração dos raios, e assim corrigir os defeitos visuais que podem decorrer de seus desvios.

Descartes (1999, p. 63), muito antes dessa acusação, já havia falado, na Regra VIII, o que se deve fazer para encontrar a proporção entre os ângulos de incidência e refração da luz, para se chegar a anaclástica:

[...] a relação entre os ângulos de incidência e os ângulos de refração depende da variação desses mesmos ângulos em razão da diferença dos meios; que essa variação ao seu redor depende do modo pelo qual o raio penetra em todo o corpo transparente e que o conhecimento da propriedade de penetrar um corpo supõe igualmente conhecida a natureza da ação da luz, e que, enfim, para compreender a ação da luz é necessário saber o que é, em geral, um poder natural, que em toda essa série é o último termo e o mais absoluto (1999, p. 63).

O poder natural do qual Descartes fala, que na ordem das razões se coloca como aquilo que é mais absoluto em relação ao que vem antes, é objeto de exame da Dióptrica e, neste ensaio científico, ele não só examina, mas também realiza demonstrações geométricas, especialmente no Discurso VIII, para aplicar as regras estabelecidas nas Regras para a direção de espírito e assim estabelecer a relação existente entre os ângulos de incidência e refração na busca da anaclástica. É importante observar que quando Descartes fala da ordem das razões se refere ao preceito da ordem, que é fundamental no procedimento dedutivo. Assim, obedecendo a ordem das razões, a dedução só é possível quando o princípio buscado é encontrado, para dele se inferir conclusões necessárias que, no caso acima mencionado, refere-se ao conhecimento do poder natural da luz determinado na Dióptrica, para assim determinar a curva anaclástica. Portanto, segundo a ordem das razões, a anaclástica só poderá ser conhecida se primeiro for conhecido o poder 
natural da luz. Mais do que isto, ele também ensina a Ferrier a construir uma máquina de talhar e polir lentes, bem como a traçar a curva anaclástica no corte dos vidros, conforme correspondência de 13 de novembro de 1629 (DESCARTES, 1996).

Diante do que foi apresentado até aqui, percebe-se que a defesa de Descartes é suficiente para nos mostrar que a acusação não procede, pois Kepler não calculou a anaclástica e sim as proporções geométricas da hipérbole, elipse e parábola, e só depois essas proporções serviriam de base para Descartes determinar a anaclástica. Sabendo então que Kepler foi importante para que Descartes pudesse determinar a anaclástica, voltemos a óptica de Alhazen, razão pela qual seus fundamentos tornaram-se essenciais para a óptica kleperiana. Sendo assim, na Introdução da obra De aspectibus, de Alhazen, mais precisamente o Livro VII, na introdução de Mark Smith, observa-se que a ascensão da ciência moderna se deve a inegável contribuição de Alhazen, que construiu sistematicamente uma teoria sobre a refração da luz. Segundo Smith, a perspectiva da atualidade de Alhazen pode ser compreendida da seguinte forma:

$$
\begin{aligned}
& \text { Implícito nesse argumento é que, se não fosse por esse } \\
& \text { impedimento teórico e conceitual [ou seja, insistir em tratar as } \\
& \text { lentes como sensitivas, não como instrumento óptico, é o que } \\
& \text { separa a óptica geométrica da física óptica], Alhazen poderia ter de } \\
& \text { fato levado a óptica ao que Bellosta se refere como modernidade. } \\
& \text { Em outras palavras, Alhazen não só lançou as bases da óptica } \\
& \text { moderna, mas também erigiu a maior parte da superestrutura. Foi } \\
& \text { Kepler, presumivelmente, quem deu os toques finais a essa } \\
& \text { superestrutura com sua teoria da imagem retiniana (apud in } \\
& \text { ALHACEN, 2010, p. xcviii). }
\end{aligned}
$$

Pesquisar a óptica moderna inevitavelmente nos remeterá a óptica alhacênica, devido a importante estrutura desenvolvida na explicação física da refração da luz, combinando determinações experimentais e mecânicas (geométricas) em sua estrutura. Segundo Smith (Ibid., p. Ixii-Ixiii), "mais importante ainda, ao tentar explicar a refração fisicamente, mesmo mecanicamente, Alhacen determinou a análise da refração em um caminho que teve importantes viradas durante o século XVII, como vários pensadores ocidentais, de Descartes a Newton, que tentaram refinar e, às vezes, redefinir o modelo". 
Se, por um lado, Alhazen falhou ao insistir tratar as lentes como sensitivas, por outro, trouxe à realidade os fundamentos de uma óptica revolucionária aperfeiçoada por Kepler e seus sucessores. Portanto, essa redefinição é dada por Descartes, quando ele encontra, na lei de refração, a relação entre os senos de incidência e refração e assim determina a curva anaclástica, com ajuda das hipérboles, parábolas e elipses de Kepler. Essa lei Alhazen não conhecia, mas com o desenvolvimento de uma teoria da visão consistente, chegou perto da lei de Snell para assim favorecer o desenvolvimento da óptica geométrica de Kepler. Desse modo, também temos uma óptica alhacênica redefinida por Newton, que constrói um modelo de comportamento da luz semelhante ao de Alhazen, principalmente quando Newton desenvolve o princípio de reciprocidade no Axioma III do Livro I da Óptica. Se o raio refratado for devolvido diretamente ao ponto de incidência, será refratado na reta descrita anteriormente pelo raio incidente (NEWTON, 2002, p. 42).

Newton faz a demonstração desse princípio na experiência do prisma, aplicando a lei de refração assim demonstrada por ele no Axioma V, do Livro I da Óptica, para daí seguir com a demonstração geométrica do comportamento da luz, atravessando o prisma:

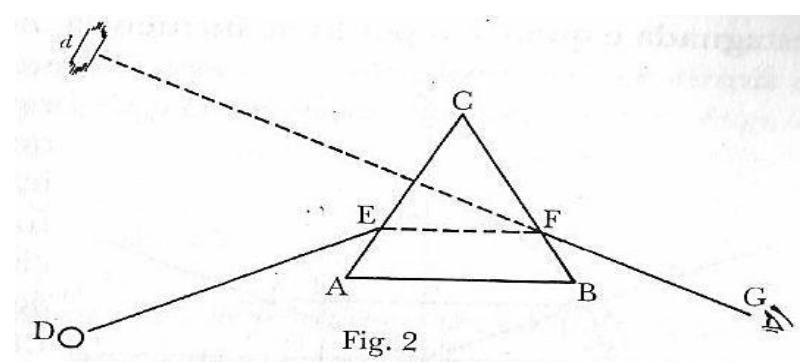

Figura 3 (NEWTON, 2002, p. 44)

Conforme a figura acima, Newton faz a demonstração da aplicação do princípio de reciprocidade, obedecendo a relação dos senos de incidência e refração para assim mostrar como se dá o comportamento da luz no prisma.

Tomando agora esse raio como $o$ raio que incide sobre 0 seguimento do lado do vidro $B C$, por onde a luz sai, achamos o raio refratado seguinte $F G$, usando 11 para 17 como proporção do seno de incidência para o seno de refração. $O$ fato é que, se o seno de incidência do ar para o vidro está para o seno de refração assim como 17 está para 11, o seno de incidência do vidro para o ar, ao contrário, tem de estar 
para o seno de refração assim como 11 está para 17, pelo Axioma III (/bid.).

Observa-se que, na Figura 3, o raio de incidência $D E$, que vem do ar, obedece a mesma proporção do seno de incidência e de refração do raio $F G$, que sai do vidro para o ar, que é de 17 para 11. Por outro lado, vemos que a proporção do seno de incidência e de refração no interior do vidro é de 11 para 17, na posição invertida de GF e ED. Logo, o que define essa relação de proporcionalidade, na aplicação do princípio de reciprocidade, depende da densidade do meio, que é o que determina a variação do desvio do raio.

Temos por ora uma breve explicação de como Newton aplica o princípio de reciprocidade com auxílio da lei de refração desconhecida por Alhazen. Desconhecêla é, certamente, uma limitação de conhecimento, pois a óptica alhacênica se restringiu a percepção sensível da luz - se nos referirmos ao avanço da trigonometria onde a lei dos senos pôde ser estabelecida. Porém, deve-se reconhecer apropriadamente o mérito de Alhazen, pois foi capaz de desenvolver o princípio de reciprocidade antes de Newton, mesmo sem ter o conhecimento da Lei de Snell e da lei de refração. Observe-se também que, no Livro VII de De aspectibus, a determinação desse princípio é realizada com aplicação do método experimental para assim chegar aos ângulos de refração em diversos meios transparentes - do ar para a água, da água para o ar, do ar para o vidro e do vidro para o ar.

Segundo Smith (apud in ALHACEN, 2010, p. xxvi), as determinações experimentais de Alhazen nos permite chegar à conclusão de que existe uma simetria no desvio do raio que entra e sai, ou vice e versa, nos meios transparentes. Essa simetria, segundo Smith trata, se estabelece da seguinte forma:

E quando o experimentador coloca os dois casos discutidos no teste experimental verá que os tamanhos dos ângulos de refração do ar para o vidro e do vidro para o ar serão sempre iguais se o ângulo da linha, que ao longo daquela luz se estende ao ponto de refração de modo normal, quando [a luz] é refratada do ar dentro do vidro, é igual ao ângulo da linha, ao longo da luz que se estende do ponto de refração de modo normal quando é refratada do vidro [no ar] (Ibid., p. 254). 
Portanto, essa demonstração do princípio de reciprocidade, mesmo que formulada empiricamente, antecipa os resultados que Newton apresentou ao fazer o uso adequado da lei de refração para assim encontrar a proporção existente nos desvios dos raios que atravessam dos meios menos densos para os mais densos e vice e versa. Smith, em sua Introdução crítica ao De aspectibus, nos mostra como Alhazen demonstra geometricamente o comportamento da luz ao aplicar o princípio de reciprocidade:

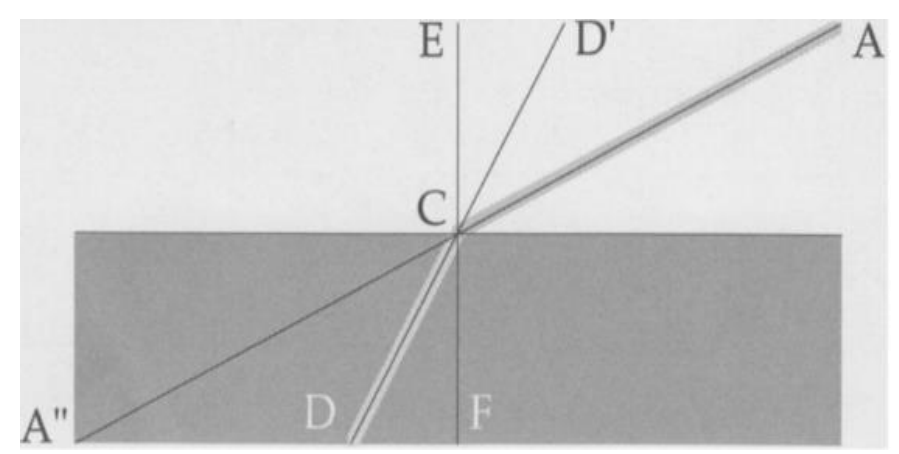

Figura 4 (lbid., p. 408).

Nessa figura, observa-se que a explicação de Alhazen segue em conformidade com a dinâmica dos raios em meios refratores também demonstrados por Newton. AC, sendo o raio que sai do meio mais denso na direção $C D$, que é o meio menos denso, sofrerá o mesmo desvio do raio DC, que sai do meio menos denso para o mais denso que é CA. Como podemos ver, a simetria dos desvios ACD é mesma em DCA sem que com isso Alhazen aplique a relação existente entre os senos de incidência e os de refração, sendo posteriormente aperfeiçoado por Newton, que corrobora o teste experimental alhacênico ao aplicar a lei de refração para demonstrar geometricamente essa simetria.

\section{Considerações finais}

Com o objetivo de estabelecer a distinção entre óptica geométrica e física óptica, a partir da análise dos antecedentes histórico-filosóficos da ciência óptica, foi possível identificar as contribuições significativas de Ptolomeu, que fizeram 
Alhazen antecipar a lei de refração, apesar da lei da proporcionalidade ter sido alcançada de forma precipitada. Ao construir o baptistir, Ptolomeu deu um passo importante para a observação dos ângulos de refração, mas, ao que parece, nem ele mesmo fez uso adequado desse instrumento para formular sua lei da proporcionalidade e assim adequá-la às observações, mas também porque não chegou a sistematizar um método experimental; além disso, sua óptica, essencialmente geométrica, sacrificou os resultados que poderiam ser produzidos pelo baptstir, que hoje é considerado instrumento atual capaz de alcançar valores muito precisos dos ângulos de incidência e refração dos raios.

Entretanto, a reformulação da óptica ptolomaica possibilitou a Alhazen estabelecer o princípio mecânico das curvas planas coordenadas para assim dar origem à física óptica, que abandona os problemas da percepção visual ao investigar a natureza da força, aceleração e desaceleração do movimento, como propriedades do fenômeno luminoso.

Apesar de Alhazen não introduzir uma teoria mecânica para explicar as propriedades da luz, limitando-se apenas a sistematização de uma ciência experimental, a explicação do comportamento do raio luminoso no meio transparente fez da sensação visual um importante aliado para a descoberta da lei de reciprocidade, sem que com ela fosse aplicada ou conhecida a lei de refração. Se a geometria tem a função de explicar o modo como se dá o desvio dos raios luminosos, vale ressaltar o reconhecimento do importante papel da mecânica para explicar a natureza da luz e suas propriedades. Mas isto só ocorreu com o surgimento da física óptica, consumada, tanto por Descartes, com a descoberta da anaclástica, e sua relação com a hipérbole de Kepler, quanto por Newton, que aplicou a lei de refração para descobrir a proporção existente entre os raios refratados e refletidos, quando percorrem um caminho recíproco, tornando o resgate da lei de reciprocidade e o princípio mecânico das curvas de Alhazen o ponto de partida para o nascimento de uma física óptica bem-sucedida. 


\section{Referências}

AL-HAYTHAM. The optics. Books I-III. Translated with introduction an commentary SABRA, A. I. London: The Warburg Institute University of London, 1989. Disponível em:

<https://archive.org/details/A.I.Sabraed.Trans.TheOpticsOflbnAlHaythamBooksIIIIO nDirectVision.TranslatedWithl>. Acesso em: 24 mar. 2017.

ALHACEN. On refraction. A Critical Edition, with English Translation and Commentary, of Book 7 of Alhacen's "De Aspectibus," the Medieval Latin Version of Ibn al-Haytham's "Kitāb al-Manāzir." Volume One. New Series, Vol. 100, No. 3. Introduction and Latin Text SMITH, Adam Mark. Philadelphia: Transactions of the American Philosophical Society, 2010. Disponível em: <http://www.jstor.org/stable/20787647>. Acesso em: 22 mar. 2017.

BLAY, Michel. La vue et la lumière : Sur quelques aspects de l'histoire de la lumière. In: Revue d'histoire des sciences, Tome 60-1, p. 119-132, janvier-juin 2007. Disponível em: <http://www.cairn.info/revue-d-histoire-des-sciences-2007-1-page119.htm>. Acesso em: 03 mai. 2017.

BOYER, Carl. The rainbow: from myth to mathematics. New Jersey: Princenton University Press, 1987.

DESCARTES, René. Oeuvres. Paris: Vrin, 1996. 11 vol. Publiées par Charles Adam et Paul Tannery.

Oeuvres et lettres. Par BRIDOUX, A. Paris: Gallimard, 1999.

KEPLER, Johannes. Optics: Paralipomena to Witelo \& Optical Part of Astronomy. Virginia: Green Lion Press, 2000.

PTOLÉMÉE, Claude. L'Optique de Claude Ptolémée: dans la version latine d'après l'arabe de l'émir Eugène de Sicile. Édité par LEJEUNE, Albert. Leiden: E. J. Brill, 1989 (Collection de Travaux de l'Academie Internationale d'Histoire des Sciences). Disponível

em:<https://books.google.com.br/books?id=wix $2 \mathrm{KmukK} 84 \mathrm{C} \&$ printsec=frontcover $\& h \mathrm{l}=\mathrm{pt}-\mathrm{PT} \&$ source$=\mathrm{gbs} \_\mathrm{ge} \_$summary_r\&cad$=0 \# \mathrm{v}=$ onepage $\& \mathrm{q} \& \mathrm{f}=\mathrm{false}>$. Acesso em: 03 abr.2017.

NEWTON, Isaac. Óptica. São Paulo: Edusp, 2002.

MACH, Ernest. The principles of physical optics an historical and philosophical treatment. USA: Dover Publications, 1926. 
MARTINHO, Marcos Paulo da Cunha. O experimento de Ptolomeu: uma introdução ao estudo da refração luminosa. Rio de Janeiro: UFRJ/IF, 2013. Originalmente apresentada como dissertação de mestrado. Universidade Federal do Rio de Janeiro. Acesso em: 19 abr. 2017, 76 páginas.

RASHED, Roshdi. Analysis and Synthesis According to Ibn al-Haytham. In: GOULD, Carol C.; COHEN, Robert S. (Org.) Artifacts, representations and social practice: essays for Marx Wartofsky. v. 154. Boston: Springer Science Business Media Dordrecht, 1994, pp. 121-140. Disponível em: <https://link.springer.com/article/10.1007\%2F978-94-011-0902-

4_8/lookinside/000.png>. Acesso em: 03 mai. 2017.

Le "Discours de la lumière" d'Ibn al-Haytham (Alhazen). Revue d'histoire des sciences et de leurs applications, tome 21, n³, pp. 197-224, 1968. Disponível em: <http://www.persee.fr/doc/rhs_0048-7996_1968_num_21_3_2560>. Acesso em: 03 mai./2017.

RODRIGUES NETO, Guilherme. Euclides e a geometria do raio visual. Scientia studia, v. $11, \quad$ n. $4, \quad 2013$, p. 873-92. Disponível em: <http://www.scielo.br/pdf/ss/v11n4/v11n4a07.pdf>. Acesso em 20 set/2017.

SARTON, George. Ancient science and modern civilization. USA: University of Nebraska Press, 1959.

Introduction to the history of science. Baltimore: Carnegie Institution of Washington, 1927.

RECEBIDO: 30/06/2020

RECEIVED: 30/06/2020

APROVADO: 26/05/2021

APPROVED: 26/05/2021 